\title{
Stark shifts and transition probabilities in Si III and Si IV spectra
}

\author{
S. Djeniže $\mathrm{e}^{1,2,3}$, M. S. Dimitrijević ${ }^{2,4}$, A. Srećković ${ }^{1,2}$, and S. Bukvić ${ }^{1,2}$ \\ 1 Faculty of Physics, University of Belgrade 11001 Belgrade, PO Box 368, Serbia, Yugoslavia \\ 2 Isaac Newton Institute of Chile, Yugoslavia Branch, Belgrade, Yugoslavia \\ ${ }^{3}$ Hungarian Academy of Sciences, Budapest, Hungary \\ 4 Astronomical Observatory, 11160 Belgrade, Volgina 7, Serbia, Yugoslavia
}

Received 24 May 2002 / Accepted 10 September 2002

\begin{abstract}
Stark shifts of nine doubly charged (Si III) and six triply charged (Si IV) silicon ion spectral lines have been measured in a linear, low-pressure, pulsed arc operated in $\mathrm{O}_{2}$ and $\mathrm{SF}_{6}$ discharges. Si III Stark shift values have been also calculated using the semiclassical perturbation formalism (SCPF) for electrons, protons and helium ions as perturbers. Transition probabilities of the spontaneous emission (Einstein's $A$ values) of nine Si III transitions have been obtained using the relative line intensity ratio (RLIR) method, not applied before in Si III spectrum, and, also, calculated using the Coulomb approximation method. The measured Si IV shift and some calculated Si III shift values present the first published data in this field.
\end{abstract}

Key words. lines: profiles - atomic data

\section{Introduction}

Atomic data such as Stark shifts $(d)$ and transition probabilities $(A)$ play an important role in the diagnostics and modeling of various cosmic and laboratory plasmas (Griem 1964, 1974; Wiese 1968; Lesage 1995; Zeippen 1995). Silicon ions are among the most abundant emitters or absorbers in many kinds of cosmic plasmas. Thus, the knowledge of the doubly (Si III) and triply (Si IV) ionized silicon spectral lines' Stark parameters and transition probabilities is necessary in various astrophysical calculations. As an example, the silicon ionisation balance can be considered as a useful tool for temperature diagnosis in B-Stars. Thus, in a work by Becker \& Butler (1990) spectral lines of Si II, Si III and Si IV emitted by non-LTE plasma have been used for temperature determination in B-Stars. In a recent publication (Monteverde et al. 2000) the ionization equilibria of Si II/Si III and Si III/Si IV have been used to observe the silicon abundance in M 33 early B Supergiants. Interstellar absorption by the young stars in the Magellanic Clouds was observed in the Si III and Si IV lines (Lehner et al. 2001). Presence of the Si III and Si IV spectral lines in the Quasar Q0122+0338 1 spectrum was observed using the Hubble Space Telescope (Papovich et al. 2000).

In the present work we will present the first Stark shifts measurements of six Si IV spectral lines and, also, the first measured Stark shift values of seven Si III spectral lines with

Send offprint requests to: S. Djeniže, e-mail: srdjan_bukvic@Softhome.net their first calculated values, performed by us, on the basis of the semiclassical perturbation formalism (SCPF) (Sahal-Bréchot 1969a,b) for electrons, protons and helium ions as perturbers. Our work also contains the first experimental Si III transition probability values for nine Si III transitions obtained in emission spectra using the relative line intensity ratio (RLIR) method, already applied in the cases of the Ar III, Ar IV (Djeniže \& Bukvić 2001), O II (Srećković et al. 2001a, 2002), Ne II (Djeniže et al. 2002a) and N III, N IV and N V (Djeniže et al. 2002b) spectra. We have also calculated the Si III transition probabilities using the Coulomb approximation method.

\section{Experiment}

The linear pulsed arc (Djeniže et al. 1992a,b, 2002a,b) was used as a plasma source. A pulsed discharge was driven in a Pyrex discharge tube of $5 \mathrm{~mm}$ inner diameter and plasma length of $7.7 \mathrm{~cm}$. Spectroscopic observations of isolated spectral lines were made along the axis of the discharge tube. Atoms of silicon were obtained as impurities by sputtering from a Pyrex discharge tube. As a driving gas, oxygen and $\mathrm{SF}_{6}$ have been used at filling pressures of $130 \mathrm{~Pa}$ and $70 \mathrm{~Pa}$, respectively. Highly ionized oxygen, sulfur and fluorine ions facilitate erosion of the glass walls of the linear part of discharge tube. Furthermore, $\mathrm{O}_{2}$ and $\mathrm{SF}_{6}$, as working gases, left the observed lines of Si III and $\mathrm{Si}$ IV isolated. The Si III lines were investigated in the oxygen plasma, while lines of $\mathrm{Si} \mathrm{IV}$ in $\mathrm{O}_{2}$ and $\mathrm{SF}_{6}$ plasmas. Discharge of the condenser of $8 \mu \mathrm{F}$ capacity charged to $4 \mathrm{kV}$ was selected for maximum efficiency in releasing silicon atoms. 
The reproducibility of the investigated silicon spectral line radiation intensities was $90 \%$, which can be taken as acceptable considering the method by which the impurity atoms were introduced.

The line profiles were recorded using a step-by-step technique described by Djeniže et al. (2002a). The Si III spectral line profiles were recorded at the same detection conditions. A sample of outputs are shown in Figs. 1 and 2.

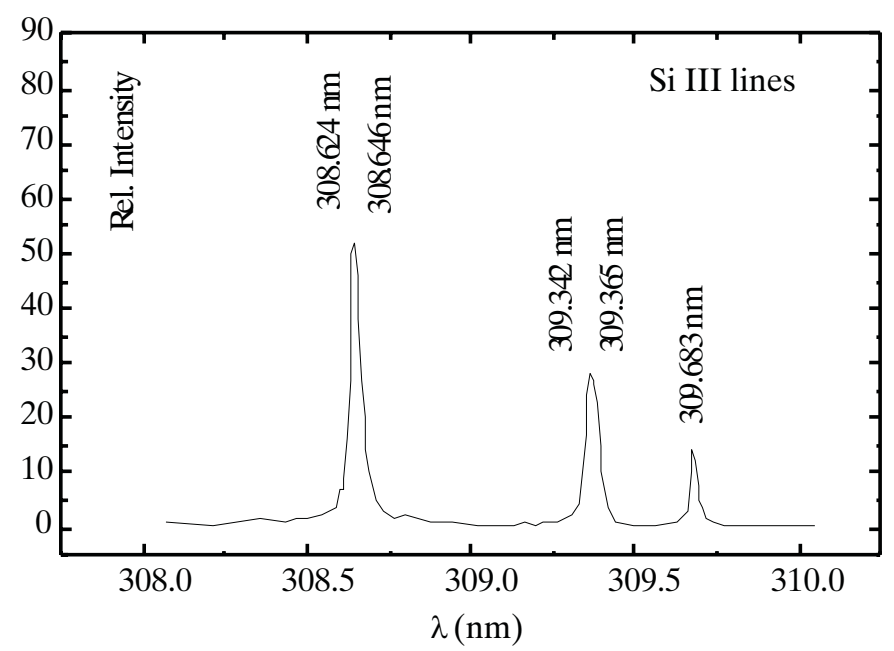

Fig. 1. Recorded spectrum with several investigated Si III lines at the 20 th $\mu$ s after the beginning of the discharge in oxygen plasma.

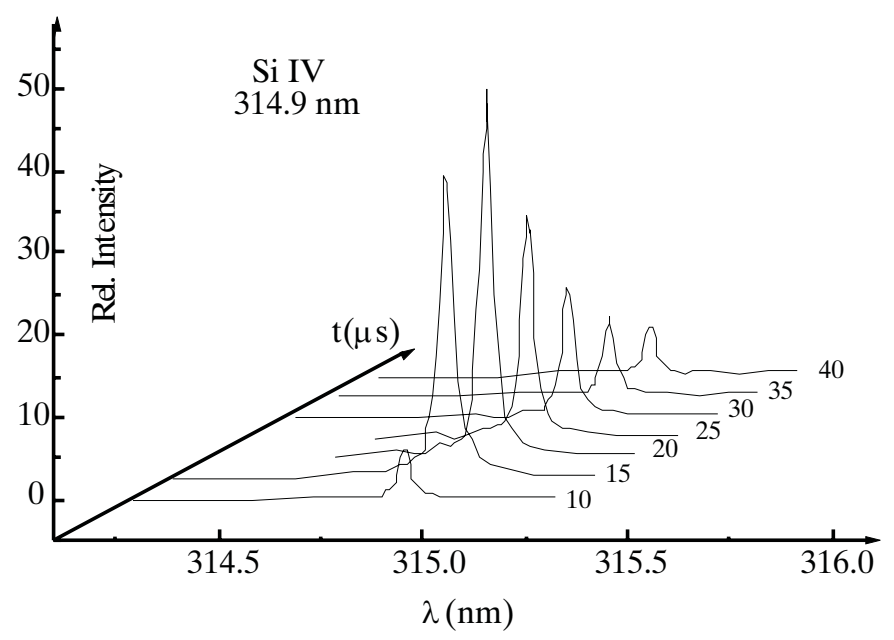

Fig. 2. Temporal evolution of the $314.9 \mathrm{~nm}$ Si IV spectral line profiles in oxygen plasma.

Total line intensity $(I)$ corresponds to the area under the line profile (within 5\%-7\% accuracy). The Si III ion concentration is low because ions are produced as impurities originating from the Pyrex discharge tube. Therefore, the influence of the selfabsorption on the total line intensity values for Si III lines can be neglected for the transition probability determination which is very important.

The plasma parameters were determined using standard diagnostic methods (Griem 1964). Thus, in the case of the oxygen plasma the electron temperature $(T)$ was determined from

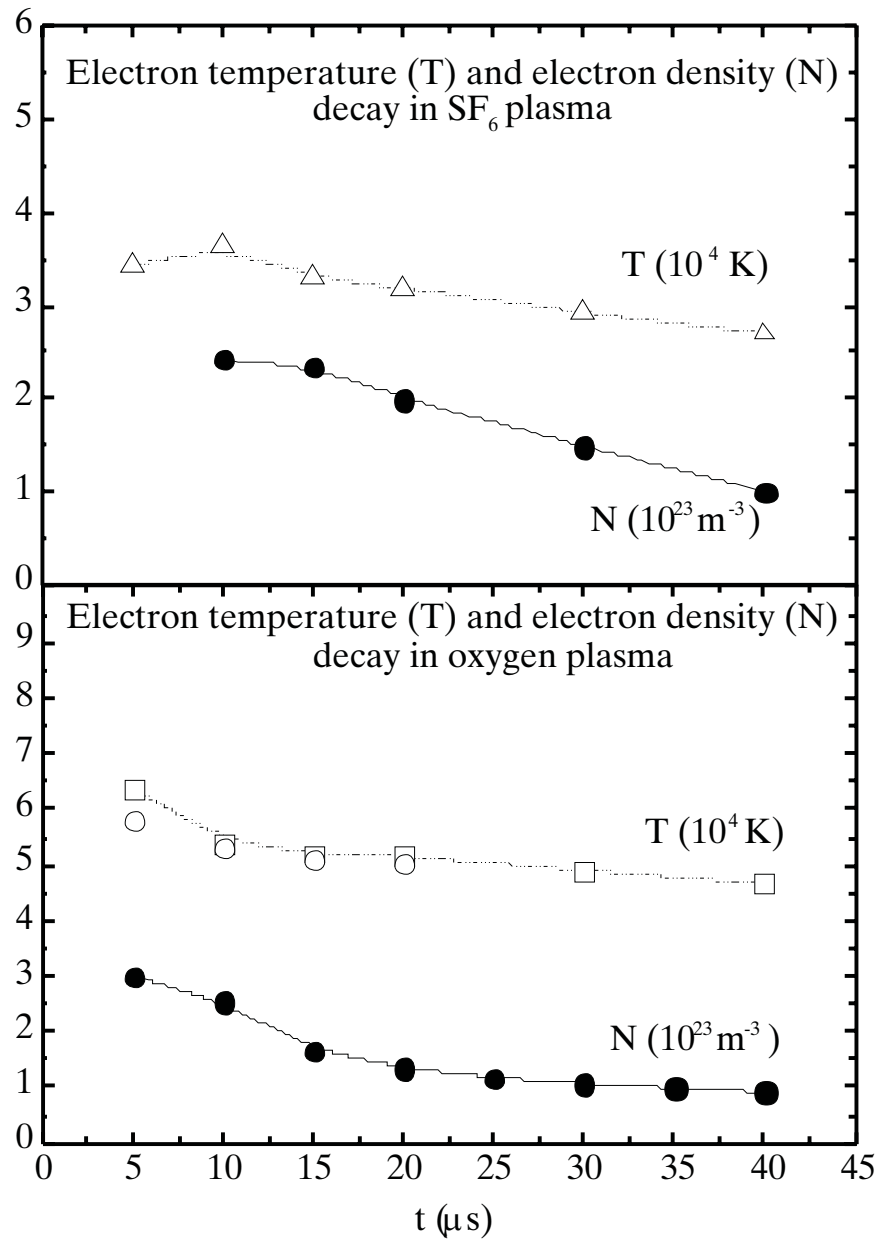

Fig. 3. Temporal evolution of the electron temperature $(T)$ and electron density $(N)$ during plasma decay. $\square$, values obtained on the basis of 9 O III line relative intensities; $O$, on the basis of the O IV/O III line intensity ratio and $\Delta$, on the basis of the S III/S II line intensity ratio.

the Boltzmann plot of the relative intensities of nine O III spectral lines $(375.9 \mathrm{~nm}, 326.1 \mathrm{~nm}, 326.5 \mathrm{~nm}, 326.7 \mathrm{~nm}, 371.5 \mathrm{~nm}$, $396.1 \mathrm{~nm}, 369.5 \mathrm{~nm}, 369.9 \mathrm{~nm}$ and $409.1 \mathrm{~nm}$ ) within an energy interval of $9.96 \mathrm{eV}$ for corresponding upper levels, and, also, from the Saha equation applied to the $375.9 \mathrm{~nm}$ O III and $307.1 \mathrm{~nm} \mathrm{O}$ IV spectral lines with an estimated error of $\pm 13 \%$ assuming the existence of local thermodynamic equilibrium (LTE), according to the criteria from Griem (1974) and Hey (1976). Here we point out that the nine investigated Si III lines have been also included in the plasma diagnostics. The Boltzmann plot based on their relative line intensities gives $T$ values (in the oxygen plasma) that agree well with the values presented in Fig. 3. The temperatures are: $51700 \mathrm{~K}$ and $51000 \mathrm{~K}$ in the 15th and 20th $\mu$ s after the beginning of the discharge. These facts indicate that the relevant Si III energy level populations remain in the LTE needed for the $A$ values calculation. In the case of the $\mathrm{SF}_{6}$ plasma, the electron temperature was determined from the ratio of the relative intensities (Saha equation) of the $334.6 \mathrm{~nm} \mathrm{~S}$ III to the $481.6 \mathrm{~nm} \mathrm{~S}$ II spectral line, supposing the existence of LTE with an estimated 
Table 1. Our measured $\left(d_{\exp }\right.$ in pm) and calculated $\left(d_{\mathrm{Th}}\right.$ in pm) electron Stark shift values at a given electron temperature $\left(T\right.$ in $\left.10^{4} \mathrm{~K}\right)$ and at $10^{23} \mathrm{~m}^{-3}$ electron density. Asteriks denote calculated values (electron shift) taken from Dimitrijević et al. (1991a). $A_{\mathrm{exp}}^{\text {rel }}$ and $A_{\mathrm{Th}}^{\text {rel }}$ denote our experimental and calculated relative transition probability (dimensionless) values. $A_{\mathrm{Th}}, A_{\mathrm{N}}$ and $A_{\mathrm{K}}$ (all in $10^{8} \mathrm{~s}^{-1}$ ) represent our calculated transition probability values and those from NIST (2002) and Kurucz (2002), respectively. Atomic data $\left(E_{\mathrm{u}}\right.$ in $\left.\mathrm{eV}\right), \lambda$ and transitions are taken from NIST (2002) and Striganov \& Sventickii (1966). Positive shift is toward the red.

\begin{tabular}{|c|c|c|c|c|c|c|c|c|c|c|}
\hline Transition & $\lambda(\mathrm{nm})$ & $E_{\mathrm{u}}$ & $T$ & $d_{\text {exp }}$ & $d_{\mathrm{Th}}$ & $A_{\exp }^{\mathrm{rel}}$ & $A_{\mathrm{Th}}^{\mathrm{rel}}$ & $A_{\mathrm{Th}}$ & $A_{\mathrm{N}}$ & $A_{\mathrm{K}}$ \\
\hline \multicolumn{11}{|l|}{ Si III } \\
\hline $3 \mathrm{p}^{1} \mathrm{P}^{\mathrm{o}}{ }_{1}-4 \mathrm{p}^{21} \mathrm{D}_{2}$ & 254.181 & 15.15 & 5.3 & $-1.0 \pm 0.8$ & & $0.087 \pm 45 \%$ & & & 0.32 & 0.158 \\
\hline $3 d^{3} D_{1}-4 p^{3} P_{o}^{o}$ & 309.683 & 21.73 & 5.3 & $-1.7 \pm 0.8$ & 0.45 & $0.696 \pm 25 \%$ & 0.917 & 1.65 & & 1.403 \\
\hline $3 d^{3} D_{3}-4 p^{3} P_{2}^{o}$ & 308.624 & 21.74 & 5.3 & & 0.45 & $0.609 \pm 25 \%$ & 0.777 & 1.40 & & 1.178 \\
\hline $4 p^{3} P_{2}^{o}-4 d^{3} D_{3}$ & 380.653 & 24.99 & 5.3 & $6.3 \pm 0.8$ & 4.4 & & 1.867 & 3.36 & 3.4 & \\
\hline $4 \mathrm{p}^{3} \mathrm{P}_{1}^{\mathrm{o}}-5 \mathrm{~s}^{3} \mathrm{~S}_{1}$ & 323.395 & 25.56 & 5.3 & $11.6 \pm 0.8$ & 11.1 & $0.630 \pm 12 \%$ & 0.594 & 1.07 & 1.3 & \\
\hline $4 p^{3} P_{2}^{o}-5 s^{3} S_{1}$ & 324.163 & 25.56 & 5.3 & $6.8 \pm 0.8$ & 11.1 & $1.00 \pm 6 \%$ & 1.00 & 1.80 & 2.3 & \\
\hline $4 d^{1} D_{2}-5 f{ }^{1} F_{3}^{o}$ & 471.665 & 27.96 & 5.3 & $1.5 \pm 0.8$ & -2.8 & $0.870 \pm 21 \%$ & 1.444 & 2.60 & 2.8 & \\
\hline $4 f^{3} F_{2}^{o}-5 g{ }^{3} G_{3}$ & 481.333 & 28.55 & 5.2 & $-12.8 \pm 0.8$ & -42.1 & $0.913 \pm 23 \%$ & 1.244 & 2.24 & & 2.910 \\
\hline $4 f^{3} \mathrm{~F}_{4}^{\mathrm{o}}-5 \mathrm{~g}^{3} \mathrm{G}_{5}$ & 482.895 & 28.55 & 5.2 & $-14.7 \pm 0.8$ & -42.1 & $0.870 \pm 23 \%$ & 1.333 & 2.40 & & 3.197 \\
\hline $3 \mathrm{~d}^{\prime}{ }^{3} \mathrm{D}_{3}^{\mathrm{o}}-4 \mathrm{p}^{\prime}{ }^{3} \mathrm{P}_{2}$ & 325.866 & 30.76 & 5.2 & $-2.5 \pm 0.8$ & & $0.891 \pm 28 \%$ & 0.550 & 0.99 & & \\
\hline \multicolumn{11}{|l|}{ Si IV } \\
\hline $4 s^{2} S_{1 / 2}-4 p^{2} P_{3 / 2}^{o}$ & 408.886 & 27.08 & 3.3 & $-1.2 \pm 0.8$ & $-0.86^{*}$ & & & & & \\
\hline $4 p^{2} \mathrm{P}_{1 / 2}^{\mathrm{o}}-4 \mathrm{~d}^{2} \mathrm{D}_{3 / 2}$ & 314.956 & 30.99 & 5.2 & $2.0 \pm 0.8$ & $1.15^{*}$ & & & & & \\
\hline $4 p^{2} \mathrm{P}_{3 / 2}^{\mathrm{o}}-4 \mathrm{~d}^{2} \mathrm{D}_{5 / 2}$ & 316.569 & 30.99 & 3.1 & $1.7 \pm 0.8$ & $1.08^{*}$ & & & & & \\
\hline $4 d^{2} \mathrm{D}_{5 / 2}-5 \mathrm{p}^{2} \mathrm{P}_{3 / 2}^{\mathrm{o}}$ & 376.245 & 34.29 & 3.2 & $1.5 \pm 0.8$ & $-0.18^{*}$ & & & & & \\
\hline $4 d^{2} \mathrm{D}_{3 / 2}-5 \mathrm{p}^{2} \mathrm{P}_{1 / 2}^{\mathrm{o}}$ & 377.315 & 34.28 & 3.2 & $0.3 \pm 0.8$ & $-0.18^{*}$ & & & & & \\
\hline $5 p^{2} P_{3 / 2}^{0}-5 d^{2} D_{5 / 2}$ & 670.121 & 36.14 & 5.2 & $7.5 \pm 0.8$ & $22.3^{*}$ & & & & & \\
\hline
\end{tabular}

error of $\pm 11 \%$. The electron temperature decay is presented in Fig. 3. Necessary atomic data were taken from NIST (2002).

Electron density $(N)$, in the case of the oxygen plasma, was measured using the well-known single laser interferometry technique for the $632.8 \mathrm{~nm} \mathrm{He}-\mathrm{Ne}$ laser wavelength with an estimated error of $\pm 6 \%$. In the case of the $\mathrm{SF}_{6}$ plasma, the electron density decay was observed by monitoring the Stark width values of the convenient $375.9 \mathrm{~nm}$ O III spectral line within an estimated error of $\pm 8 \%$. Oxygen ions produced as impurities in $\mathrm{SF}_{6}$ discharge, due to their low concentration, give convenient Stark width values because of the absence of self-absorption. Corresponding $N$ values, predicted by semiclassical theory (Griem 1974), were taken from Srećković et al. (2001b). The electron density decay is also presented in Fig. 3. Taking into account the temporal dependence of $T$ and $N$ and the criteria for the existence of LTE, one can conclude that relevant $\mathrm{Si}$ III ion level populations remain in LTE up to the 60th $\mu \mathrm{s}$ after the beginning of the discharge.

\section{Stark shift measurements}

The Stark shifts were measured relative to the unshifted spectral lines emitted by the same plasma (Djeniže et al. 2002a, and references therein). Stark shift data are determined with $\pm 0.8 \mathrm{pm}$ error at a given $N$ and $T$. Our measured $\left(d_{\mathrm{exp}}\right)$ Stark shifts are presented in Table 1.

\section{Transition probability measurements}

In the case where plasma remains at LTE, the well-known formula (Griem 1964, 1974; Rompe \& Steenbeck 1967; Wiese 1968)

$\left(I_{1} / I_{2}\right)_{\mathrm{EXP}}=\left(A_{1} g_{1} \lambda_{2} / A_{2} g_{2} \lambda_{1}\right) \exp \left(\Delta E_{21} / k T\right)$

can be used for a comparison between measured relative line intensity ratios and corresponding calculated values, taking into account the validity of the Boltzmann distribution for the population of the excited levels in emitters. In this expression, $I$ denotes the measured relative intensity, $\lambda$ the wavelength of the transition, $A$ the transition probability of the spontaneous emission, $E$ the excitation energy from the ground energy level, and $g$ the corresponding statistical weight. $T$ is the electron temperature of the plasma in LTE and $k$ is the Boltzmann constant. On the basis of the measured relative line intensity ratio and determined electron temperature, Eq. (1) gives the possibility to obtain the ratio of the corresponding transition probabilities or the possibility of the determination of the particular transition probability value relative to the selected reference $A$ values. As reference $A$ value the transition probability corresponding to the Si III $324.163 \mathrm{~nm}$ transition was chosen. This line is the most intense and has the highest reproducibility among the investigated Si III spectral lines. Our experimental relative $A$ values ( $A_{\exp }^{\text {rel }}$ ) are presented in Table 1 with estimated accuracies that contain the uncertainties of the line intensity and electron temperature determinations and the uncertainties 
Table 2. Electron (a), proton (b) and helium ion (c) Stark shifts (in pm) calculated by using semiclassical perturbation formalism (SCPF) (Eqs. (4)-(6) in Djeniže et al. 2002a) for the Si III spectral lines at $10^{23} \mathrm{~m}^{-3}$ perturber density and electron temperatures from $10000 \mathrm{~K}$ to 300 $000 \mathrm{~K} .\langle\lambda\rangle$ is the mean wavelength in the multiplet. Positive shift is toward the red.

\begin{tabular}{|c|c|c|c|c|c|c|c|c|}
\hline Transition & $<\lambda>(\mathrm{nm})$ & $T\left(10^{4} \mathrm{~K}\right):$ & 1 & 2 & 5 & 10 & 15 & 30 \\
\hline \multirow[t]{3}{*}{$3 d^{3} D-4 p^{3} P^{o}$} & 309.07 & & a: 0.34 & 0.50 & 0.44 & 0.57 & 0.50 & 0.48 \\
\hline & & & b: 0.08 & 0.17 & 0.31 & 0.42 & 0.47 & 0.56 \\
\hline & & & c: 0.14 & 0.32 & 0.61 & 0.85 & 0.95 & 1.14 \\
\hline \multirow[t]{3}{*}{$4 p^{3} P^{o}-4 d^{3} D$} & 380.25 & & a: 4.17 & 3.74 & 4.38 & 3.76 & 3.71 & 3.37 \\
\hline & & & b: 1.33 & 2.14 & 3.20 & 3.85 & 4.28 & 4.97 \\
\hline & & & c: 2.32 & 4.00 & 6.31 & 7.82 & 8.61 & 10.0 \\
\hline \multirow[t]{3}{*}{$4 s^{3} S-4 p^{3} P^{o}$} & 456.14 & & $\mathrm{a}:-1.74$ & -2.31 & -2.11 & -2.34 & -2.18 & -2.02 \\
\hline & & & $\mathrm{b}:-0.46$ & -0.86 & -1.46 & -1.82 & -2.04 & -2.44 \\
\hline & & & $\mathrm{c}:-0.81$ & -1.63 & -2.90 & -3.69 & -4.12 & -4.92 \\
\hline \multirow[t]{3}{*}{$4 p^{3} P^{o}-5 s{ }^{3} S$} & 323.88 & & a: 21.5 & 15.7 & 11.7 & 9.33 & 7.98 & 6.77 \\
\hline & & & b: 1.98 & 3.03 & 4.26 & 5.12 & 5.52 & 6.38 \\
\hline & & & c: 3.39 & 5.56 & 8.31 & 10.3 & 11.2 & 12.8 \\
\hline \multirow[t]{3}{*}{$4 d^{1} D-5 f{ }^{1} F^{o}$} & 471.80 & & a: -7.4 & -4.53 & -2.85 & -2.06 & -1.44 & -1.57 \\
\hline & & & $\mathrm{b}:-9.61$ & -14.1 & -19.6 & -23.1 & -25.3 & -28.3 \\
\hline & & & c: & & -38.0 & -46.7 & -50.6 & -56.8 \\
\hline $4 f^{3} F^{o}-5 g{ }^{3} G$ & 482.35 & & $\mathrm{a}:-38.6$ & -42.4 & -42.2 & -36.6 & -38.5 & -34.1 \\
\hline
\end{tabular}

of the calibration procedure. $A_{\exp }^{\text {rel }}$ represent averaged values obtained during plasma decay in the time interval for which the criteria of the existence of the LTE is fulfilled. Our $A_{\exp }^{\text {rel }}$ values provide the possibility for future comparison with absolute data as well as with data presented in relative form.

\section{Method of calculation}

\subsection{Stark shifts}

The semiclassical perturbation formalism, as well as the corresponding computer code (Dimitrijević \& Sahal-Bréchot 1996a,b), has been updated and optimized several times (Dimitrijević \& Sahal-Bréchot 1996b, 1984; Sahal-Bréchot 1974; Fleurier et al. 1977; Dimitrijević et al. 1991b). The calculation procedure, with the discussion of updates and validity criteria, has been briefly reviewed in Dimitrijević \& Sahal-Bréchot (1996a,b) (see also Djeniže et al. 2002a). The formulae for the ion-impact widths and shifts are analogous to Eqs. (4)-(6) in Djeniže et al. (2002a), without the resonance contribution to the width. The difference in calculation of the corresponding transition probabilities and phase shifts as functions of the impact parameter in Eqs. (5), (6) is in the ion perturber trajectories which are influenced by the repulsive Coulomb force instead of an attractive one as for electrons. Atomic energy levels were taken from Martin \& Zalubas (1983). Note that in the Si III spectrum many of the known terms are affected by configuration interactions and some needed here are not experimentally determined. Consequently, the obtained theoretical results might have errors larger than usual for the semiclassical perturbation method $( \pm 30 \%)$.
Our calculated electron, proton and helium ion Stark shift values $\left(d_{\mathrm{Th}}\right)$ are presented in Tables 1 and 2.

\subsection{Transition probabilities}

Due to its simplicity, the Coulomb approximation method of Bates \& Damgaard (Bates \& Damgaard 1949; Oertel \& Shomo 1968 ) for the calculation of the Einstein $A$ values (oscillator strengths) is often used in spite of the existence of more sophisticated methods. It is used particularly for complex calculations of e.g. line broadening parameters or stellar opacity. It is of interest therefore to compare oscillator strengths calculated with Coulomb approximation, with experimental values, as well as with theoretical ones obtained with sophisticated methods. This is particularly interesting for Si III, since many of the known terms in this spectrum are affected by configuration interactions. We took into account here that $3 \mathrm{~s} 4 \mathrm{f}^{3} \mathrm{~F}^{\mathrm{o}}$ term has $23 \%$ of $3 \mathrm{p} 3 \mathrm{~d}^{3} \mathrm{~F}^{\mathrm{o}}$ and that $3 \mathrm{~s} 5 \mathrm{f}^{1} \mathrm{~F}^{\mathrm{o}}$ has a purity of $55 \%$, while $31 \%$ are 3pnd ${ }^{1} \mathrm{~F}^{\mathrm{o}}$ and $14 \%$ is not determined. Consequently, the accuracy of the oscillator strength of the $471.67 \mathrm{~nm}$ line is lower than the others. Moreover, the composition of the $3 \mathrm{~s} \mathrm{~g}^{3} \mathrm{G}$ term is not determined, so that oscillator strength of the $481.33 \mathrm{~nm}$ and $482.90 \mathrm{~nm}$ lines might be affected by the configuration interaction. The same discussion holds for the accuracy of the Stark shifts of these lines, which are more uncertain than other results. Our calculated $A$ values $\left(A_{\mathrm{Th}}\right)$ are presented in Table 1.

\section{Results and discussion}

The results of the measured Stark shift $\left(d_{\exp }\right)$ and relative transition probability ( $\left.A_{\text {exp }}^{\text {rel }}\right)$ as well as the calculated transition probability $\left(A_{\mathrm{Th}}\right)$ values are shown in Table $1 . A_{\mathrm{Th}}^{\text {rel }}$ represent our 
calculated relative transition probability values. Our calculated Stark shift values $\left(d_{\mathrm{Th}}\right)$ are presented in Table 2.

On the basis of Tables 1 and 2 one can conclude that our measured $\left(d_{\exp }\right)$ and calculated $\left(d_{\mathrm{Th}}\right)$ Si III Stark shift values agree in the case of the lines that belong to the $4 \mathrm{p}^{3} \mathrm{P}^{\mathrm{o}}-4 \mathrm{~d}^{3} \mathrm{D}$ and $4 \mathrm{p}^{3} \mathrm{P}^{\mathrm{o}}-5 \mathrm{~s}^{3} \mathrm{~S}$ transitions within the experimental accuracy and uncertainties of the calculations. In the case of the $4 \mathrm{f}^{3} \mathrm{~F}^{\mathrm{o}}-5 \mathrm{~g}^{3} \mathrm{G}$ transition, the measured and calculated shifts have the same negative sign, but the calculated ones are about 3 times larger. This could be explained by the unknown composition of the $3 \mathrm{~s} 5 \mathrm{~g}^{3} \mathrm{G}$ term of these Si III lines and the unknown composition of $\mathrm{ng}^{3} \mathrm{G}$ and $\mathrm{nh}^{3} \mathrm{H}^{\circ}$ perturbing terms. Experimental $d$ values for these lines obtained by González et al. (2000) also have a negative sign and lie below our calculated ones. Measured and calculated $d$ values of the lines $309.683 \mathrm{~nm}$ and $471.665 \mathrm{in}$ the $3 \mathrm{~d}^{3} \mathrm{D}-4 \mathrm{p}^{3} \mathrm{P}^{\mathrm{o}}$ and $4 \mathrm{~d}^{1} \mathrm{D}-5 \mathrm{f}^{1} \mathrm{~F}^{\mathrm{o}}$ transitions, respectively, are small but have a different sign. This discrepancy can be considered as tolerable, taking into account the accuracy $( \pm 0.8 \mathrm{pm})$ of the experimental values and the uncertainties of the theoretical predictions related to the atomic data necessary for the Stark shift calculations. Incompleteness of the experimental perturbing energy levels in the case of the Si III $254.181 \mathrm{~nm}$ and $325.866 \mathrm{~nm}$ spectral lines is such that the semiclassical perturbation calculation results will be of very poor accuracy. On the basis of the calculated Si III Stark shift values (see Table 2), one can conclude that at electron temperatures below $30000 \mathrm{~K}$, the electron Stark shift is dominant. In the plasmas with electron temperatures higher than $50000 \mathrm{~K}$, proton and helium Stark shifts play an important role. The Stark shift generated by helium ions is about two times higher than the shift generated by protons. These results can be important in astrophysical plasmas where protons and helium ions represent the main plasma components.

In the case of the Si IV lines our measured Stark shifts and the calculated ones presented by Dimitrijević et al. (1991a) are very small and mutually agree very well within the experimental accuracy and uncertainties of the calculations. The only exception is the $d$ value of the higher lying $5 \mathrm{p}^{2} \mathrm{P}^{\mathrm{o}}-5 \mathrm{~d}^{2} \mathrm{D}$ $(670.121 \mathrm{~nm})$ transition where the $d_{\mathrm{Th}}$ is higher than the measured ones by about 3 times. It should be pointed out that the $d_{\text {Th }}$ values taken from Dimitrijević et al. (1991a) are also calculated on the basis of the semiclassical perturbation formalism (SCPF).

In the case of the transition probability values we can notice reasonable agreement between $A_{\mathrm{exp}}^{\text {rel }}$ and $A_{\mathrm{Th}}^{\text {rel }}$ values within the accuracies of the experiment (12-45\%) and uncertainties of the calculations $(<40 \%)$. The only exception is the $325.866 \mathrm{~nm}$ transition where the experimental $A$ value is about 2 times higher than the calculated ones. It should be pointed out that our results for the mentioned transition are the first published data. Our calculated $A$ values $\left(A_{\mathrm{Th}}\right)$ on the basis of the Coulomb approximation method agree with tabulated values in NIST (2002) and Kurucz (2002) predicted with about 50\% uncertainties in NIST values (NIST 2002). Our smaller $A_{\text {Th }}$ values in the case of the $481.333 \mathrm{~nm}$ and $482.895 \mathrm{~nm}$ transitions in comparison to the $A_{\mathrm{K}}$ values can be explained taking into account the cited (in Chap. 5.2) approximations used for our calculations. It should be pointed out that the ratio of the $A_{\mathrm{exp}}^{\mathrm{rel}}, A_{\mathrm{Th}}$ and $A_{\mathrm{N}}$ values related to the $323.395 \mathrm{~nm}$ and $324.163 \mathrm{~nm}$ transitions in the Si III $4 \mathrm{p}^{3} \mathrm{P}^{0}-5 \mathrm{~s}^{3} \mathrm{~S}$ multiplet are in very good mutual agreement (within 10\%). They are: $0.630,0.594$ and 0.565 , respectively. This fact confirm validity of our choice of the reference $A$ value.

\section{Conclusion}

Generally, we have found satisfying agreement between measured and theoretical Stark shift values calculated on the basis of the semiclassical perturbation formalism (SCPF), especially in the case of the Si IV spectral lines. Difficulties about the knowledge of the perturbing energy levels increase the uncertainties of some calculated Si III Stark shift values, explaining the existing disagreement between some measured and calculated Stark shift values. Taking into account the agreement between measured and calculated finite $d$ values, we recommend the $380.653,323.395$ and $324.163 \mathrm{~nm} \mathrm{Si} \mathrm{III} \mathrm{spectral} \mathrm{lines} \mathrm{as}$ lines with convenient Stark shift values useful in astrophysical plasma diagnostics. Our experimental and calculated Si III transition probability values are in tolerable mutual agreement, within $40 \%$ on average.

Acknowledgements. This work is a part of the projects "Determination of the atomic parameters on the basis of the spectral line profiles" and "Influence of collision processes on astrophysical plasma lineshapes" supported by the Ministry of Science, Technologies and Development of the Republic of Serbia. S. Djeniže is grateful to the Foundation “Arany János Közalapitvány” Budapest, Hungary.

\section{References}

Bates, D. R., \& Damgaard, A. 1949, Trans. Roy. Soc. London, Ser. A, 242,101

Becker, S. R., \& Butler, K. 1990, A\&A, 235, 326

Dimitrijević, M. S., \& Sahal-Bréchot, S. 1984, JQSRT, 31, 301

Dimitrijević, M. S., Sahal-Bréchot, S., \& Bommier, V. 1991a, A\&AS, 89,591

Dimitrijević, M. S., Sahal-Bréchot, S., \& Bommier, V. 1991b, A\&AS, 89, 581

Dimitrijević, M. S., \& Sahal-Bréchot, S. 1996a, Phys. Scr., 54, 50

Dimitrijević, M. S., \& Sahal-Bréchot, S. 1996b, A\&A, 119, 369

Djeniže, S., Srećković, A., \& Labat, J. 1992a, A\&A, 253, 632

Djeniže, S., Srećković, A., Labat, J., Purić, J., \& Platiša, M. 1992b, J. Phys. B Atom. Molec. Optic., 25, 785

Djeniže, S., \& Bukvić, S. 2001, A\&A, 365, 252

Djeniže, S., Milosavljević, V., \& Dimitrijević, M. S. 2002a, A\&A, 382, 359

Djeniže, S., Srećković, A., \& Bukvić, S. 2002b, Eur. Phys. J. D, 20, 11

Fleurier, C., Sahal-Bréchot, S., \& Chapelle, J. 1977, JQSRT, 17, 595

González, V. R., Aparicio, J. A., del Val, J. A., \& Mar, S. 2000, A\&A, 363,1177

Griem, H. R. 1964, Plasma Spectroscopy (McGraw-Hill Inc. New York)

Griem, H. R. 1974, Spectral Line Broadening by Plasmas (Acad. Press, New York)

Hey, J. D. 1976, JQSRT, 16, 69

Kurucz, R. L. 2002, Harvard-Smitshonian Center for Astrophysics, CD ROM 23 
Lesage, A. 1995, ASP Conf. Ser. 78, ed. S. J. Adelman, \& W. L. Wiese (Astronomical Society of the Pacific, San Francisco), 161

Lehner, N., Sembach, K. R., Dufton, P. L., Rolleston, W. R. J., \& Keenan, F. P. 2001, ApJ, 551, 781

Martin, W. C., \& Zalubas, R. 1983, J. Phys. Chem. Ref. Data, 12, 323

Monteverde, M. I., Herrero, A., \& Lennon, D. J. 2000, ApJ, 545, 813

NIST 2002, Atomic Spectra Data Base Lines http://physics.nist.gov

Oertel, G. K., \& Shomo, L. P. 1968, ApJS, 16, 175

Papovich, C., Norman, C. A., Bowen, D. V., et al. 2000, ApJ, 531, 654

Rompe, R., \& Steenbeck, M. 1967, Ergebnisse der Plasmaphysik und der Gaselektronik, Band 1 (Akademie Verlag, Berlin)

Sahal-Bréchot, S. 1969a, A\&A, 1, 91
Sahal-Bréchot, S. 1969b, A\&A, 2, 322

Sahal-Bréchot, S. 1974, A\&A, 35, 321

Srećković, A., Drinčić, V., Bukvić, S., \& Djeniže, S. 2001a, Phys. Scr., 63, 306

Srećković, A., Dimitrijević, M. S., \& Djeniže, S. 2001b, A\&A, 371, 354

Srećković, A., Djeniže, S., \& Bukvić, S. 2002, Phys. Scr., 65, 359

Striganov, R. A., \& Sventickii, N. S. 1966, Tablicy Spektralnych Linij (Atomizdat, Moskva)

Wiese, W. L. 1968, Meth. Exper. Phys. 7B, ed. B. Bederson, \& W. L. Fite (Academic Press, New York)

Zeippen, C. J. 1995, Phys. Scr., 58, 43 